\title{
Três espécies novas de Centronodus Funkhouser (Homoptera, Membracidae, Centronodinae) ${ }^{1}$
}

\author{
Randal Lopes Barreira ${ }^{2}$ \\ Albino Morimasa Sakakibara ${ }^{3}$
}

\begin{abstract}
Three new species of Centronodus Funkhouser (Homoptera, Membracidae, Centronodinae). Centronodus bilobatus sp. n. (Ecuador), Centronodus bolivianus sp. n. (Bolivia) and Centronodus magnificus sp. n. (Brazil), are described and illustrated.

KEY WORDS. Homoptera, Membracidae, Centronodinae, Centronodus, taxonomy
\end{abstract}

O gênero Centronodus foi criado por FUNKHOUSER (1930) para incluir duas espécies suas: Centronodus denticulus (espécie-tipo) (Costa Rica) e Centronodus flavus (Brasil, Pernambuco). FonSECA (1940) revisou o gênero e acrescentou mais uma espécie, Centronodus rochalimai (Brasil, São Paulo). FonSECA (1974) descreveu outra, do Pará, Centronodus intermedius (Brasil). DEITZ (1975), ao apresentar a classificação dos membracídeos, criou a tribo Centronodini, dentro da subfamília Stegaspinae [ $\mathrm{sic}]$ Haupt, 1929; incluindo na tribo os gêneros Centronodus Funkhouser e Postanomus Funkhouser. DEITZ \& DiETRICH (1993) elevaram Centronodini Deitz, 1975 para a categoria de subfamília, Centronodinae, por sua vez distinta de Stegaspidinae Haupt, 1929; e transferiram Paracentronodus Sakakibara, 1971 (Centrotinae Amyot \& Serville), para dentro de Centronodinae.

Dentre os espécimes pertencentes à Coleção de Entomologia Pe. J.S. Moure, Departamento de Zoologia, Universidade Federal do Paraná (DZUP) e do National Museum of Natural History, Washington, D.C. (NMNH), foram descobertas mais três espécies novas descritas a seguir: Centronodus bilobatus sp. n. (Equador), Centronodus bolivianus sp. n. (Bolívia) e Centronodus magnificus sp. n. (Brasil).

\section{Chave para as espécies}

1. Margem anterior da elevação dorsal arredondada . . . . . . . . . . . . . 2

- Margem anterior da elevação dorsal sinuosa . .................. 3

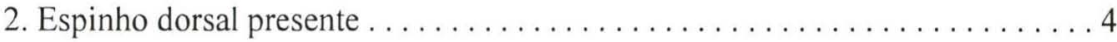

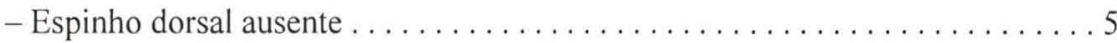

3. Processos supra-umerais com as pontas agudas ........ C. rochalimai Fonseca - Processos supra-umerais com as pontas alargadas ........ C. intermedius Fonseca

1) Contribuição número 1239 do Departamento de Zoologia, Universidade Federal do Paraná.

2) Curso de Pós-Graduação em Entomologia, Universidade Federal do Paraná. Bolsista da CAPES.

3) Departamento de Zoologia, Universidade Federal do Paraná. Caixa Postal 19020, 81531-990 Curitiba, Paraná, Brasil. Bolsista do CNPq. 
4. Processos supra-umerais mais ou menos achatados e foliáceos para o ápice .... C. magnificus sp. $\mathbf{n}$.

- Processos supra-umerais prismáticos $\ldots \ldots \ldots \ldots \ldots \ldots \ldots \ldots \ldots$

5. Ápices dos processos supra-umerais simples . . . . . . . C. flavus Funkhouser - Ápices dos processos supra-umerais bilobados .......... C. bilobatus $\mathbf{s p .} \mathbf{n}$. 6. Elevação dorsal em arco regular, com declives anterior e posterior suaves ..... C. denticulus Funkhouser

- Elevação dorsal acentuadamente mais pronunciada anteriormente, com o declive anterior abrupto e o posterior de forma gradativa .....C. bolivianus $\mathbf{s p .} \mathbf{n}$.

\section{Centronodus bilobatus sp. $\mathbf{n}$.}

Figs 1, 4-6

Diagnose. Porte relativamente pequeno, com o pronoto curto terminando antes do ápice do clavo; processos supra-umerais reduzidos, distalmente bilóbados; elevação dorsal obsoleta, não sobressaindo aos processos supra-umerais em vista lateral.

Medidas (mm). Fêmea. Comprimento total, 7,83; largura da cabeça, 3,50; comprimento da cabeça, 1,33; comprimento do pronoto, 5,83; largura entre os ângulos umerais, 4,42; comprimento dos processos supra-umerais, 1,25; distância entre os ápices dos processos supra-umerais, 3,75; comprimento dos processos supra-umerais, 0,17 ; altura da elevação dorsal, 1,33; comprimento das tégminas, 6,67; comprimento das asas, 6,08.

Descrição. Holótipo fêmea. Cabeça sub-quadrangular, quase três vezes mais larga que longa, levemente pontuada, de coloração acastanhada e com manchas negras; clípeo mais largo que longo, triangular, no mesmo nível das margens dos lóbulos supra-antenais, metade distal voltada para trás; sutura epistomal arqueada; lóbulos supra-antenais com superfície plana, textura lisa, com margens levemente sinuosas; espaços interocelar e ocelo-oculares planos; ocelos de cor âmbar, situados um pouco abaixo da linha imaginária que passa pelo centro dos olhos, mais próximos entre si do que dos olhos; sutura coronal não atingindo a base superior do clípeo; margem superior do vértice reta. Pronoto com o mesmo padrão de coloração e pilosidade da cabeça, com pontuação homogênea; carena dorsal saliente; lóbulos pós-oculares com superfície rugosa; metopídio plano; distância entre os ângulos umerais maior que a largura entre os ápices dos processos supra-umerais; processos supra-umerais bilobados, dirigidos para cima, com carena somente na metade distal; duas elevações dorsais pequenas, arredondadas, logo em seguida aos processos supra-umerais; elevação dorsal pouco pronunciada, rebaixada, com declive anterior acentuado e o posterior gradual, terminando pouco antes do ápice do clavo; região pré-apical com uma faixa bege. Tégminas com a mesma coloração do pronoto, apresentando pequenas áreas translúcidas. Asas hialinas com venação castanho-escura. Pernas acastanhadas; tíbias amareladas com faixas transversas escuras.

Macho. Desconhecido

Revta bras. Zool. 18 (Supl. 1): 243 - 250, 2001 


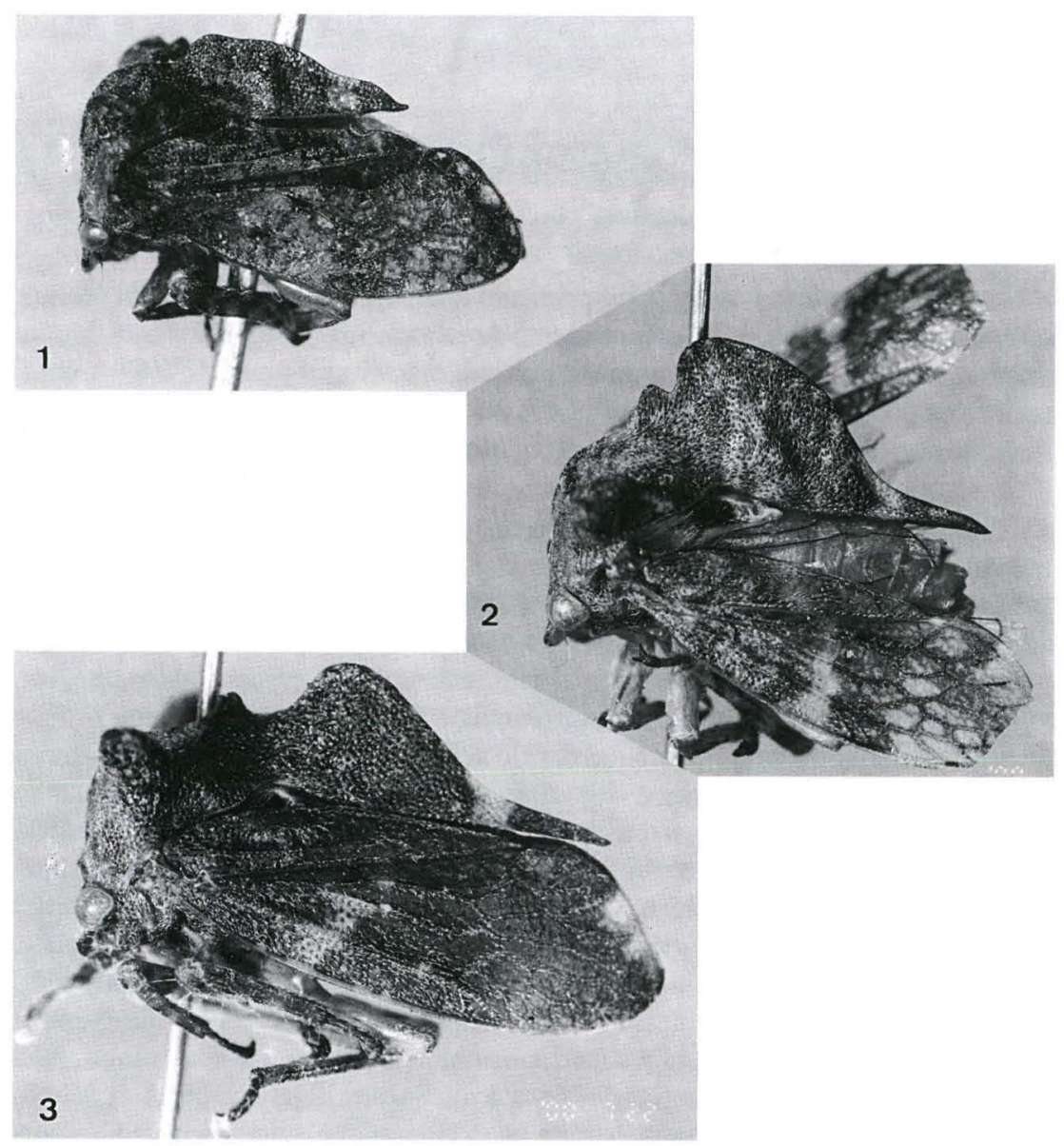

Figs 1-3. (1) Centronodus bilobatus sp. n.; (2) Centronodus bolivianus sp. n.; (3) Centronodus magnificus sp. $\mathbf{n}$.

Material examinado. Holótipo fêmea, com os seguintes dados: "Ecuador: Napo; Tiputini Biodiversity Station. 00³7'55"S, 7608’39"W 216.1 m; 4 July 1998 T.L. Erwin, et al.." (USNM).

Etimologia. O nome específico é alusivo aos processos supra-umerais bilobados.

Comentários. Esta espécie difere bastante das outras, principalmente pelo seu tamanho e pela forma do pronoto; os processos supra-umerais são curtos e bilobados e a elevação dorsal obsoleta; as tégminas e parte final do pronoto semelhantes a $C$. flavus, diferindo nos demais caracteres. 


\section{Centronodus bolivianus sp. $\mathbf{n}$.}

Figs 2, 7-10

Diagnose. De porte médio, com os processos supra-umerais bem desenvolvidos, aproximadamente horizontais; elevação dorsal projetada bem acima dos processos supra-umerais, precedida por um pequeno dente rombo; porção distal afilada, terminando na altura do ângulo interno das tégminas.

Medidas (mm). Macho. Comprimento total, 8,67; comprimento do pronoto, 7,50; largura da cabeça, 3,75; comprimento da cabeça, 1,67; largura entre os ângulos umerais, 3,75; distância entre os ápices dos processos supra-umerais, 5,67; comprimento dos processos supra-umerais, 1,67; altura do espinho dorsal, 0,83; altura da elevação dorsal, 2,50; comprimento das tégminas, 7,75; comprimento das asas, 5,67.

Descrição. Holótipo macho. Cabeça de forma sub-quadrangular, duas vezes mais larga que longa, densamente pontuada, com pêlos fulvos; clípeo duas vezes mais longo que largo, de forma sub-losângica, com o bordo inferior ultrapassando ligeiramente a margem dos lóbulos supra-antenais, com o ápice voltado para trás; sutura epistomal arqueada; lóbulos supra-antenais com superfície plana, rugosa e margens foliáceas, sinuosas; espaço ocelo-ocular plano; espaço interocelar convexo; ocelos amarelo-mélicos, mais próximos entre si do que dos olhos, situados na altura da linha imaginária que passa pelo centro dos olhos. Pronoto densamente pontuado com manchas escuras e claras irregulares, com pontos pretos de tamanhos iguais, visto frontalmente, destacando uma faixa larga marrom, horizontal, na parte superior da região frontal; carena dorsal saliente; lóbulos pós-oculares com superfície pontuada; metopídio plano; distância entre os ângulos umerais menor que a largura entre os ápices dos processo supra-umerais; processos supra-umerais de forma prismática, com a base larga, direcionados para os lados e para trás, ligeiramente voltados para cima, com carena anterior pronunciada em toda a sua extensão, carena posterior aparente, com a superfície pontuada; espinho dorsal rombo, inclinado para frente; margem anterior da elevação dorsal arredondada, declive posterior leve, região pré-apical com uma estreita faixa amarelada; ápice do pronoto gradativamente agudo, terminando na altura do ângulo interno das tégminas. Escutelo visível lateralmente. Tégminas com a mesma coloração do pronoto, com diversas áreas transparentes; parte apical enfumaçada, translúcida. Asas transparentes com venação acastanhada. Abdômen com as partes laterais vermelho-brasa, e a parte ventral castanho-clara. Pernas castanho-claras com faixas escuras.

Fêmea. Desconhecida.

Material examinado. Holótipo macho, com os seguintes dados: "Santa Cruz de La Sierra - Bolívia, 12: XII:1956, M. Alvarenga leg." (DZUP).

Etimologia. O nome específico é alusivo à localidade de origem do exemplar.

Comentários. Esta espécie é parecida com $C$. intermedius Fonseca e $C$. rochalimai Fonseca pela forma geral do pronoto. Difere entretanto, pela elevação dorsal pronunciada e largamente arredondada em vista lateral; o espinho dorsal é rombo e bem junto da elevação dorsal; os processos supra-umerais são bem mais curtos. 


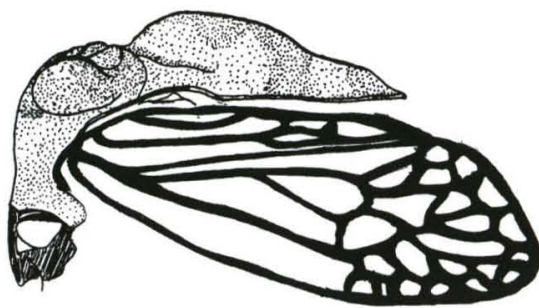

4
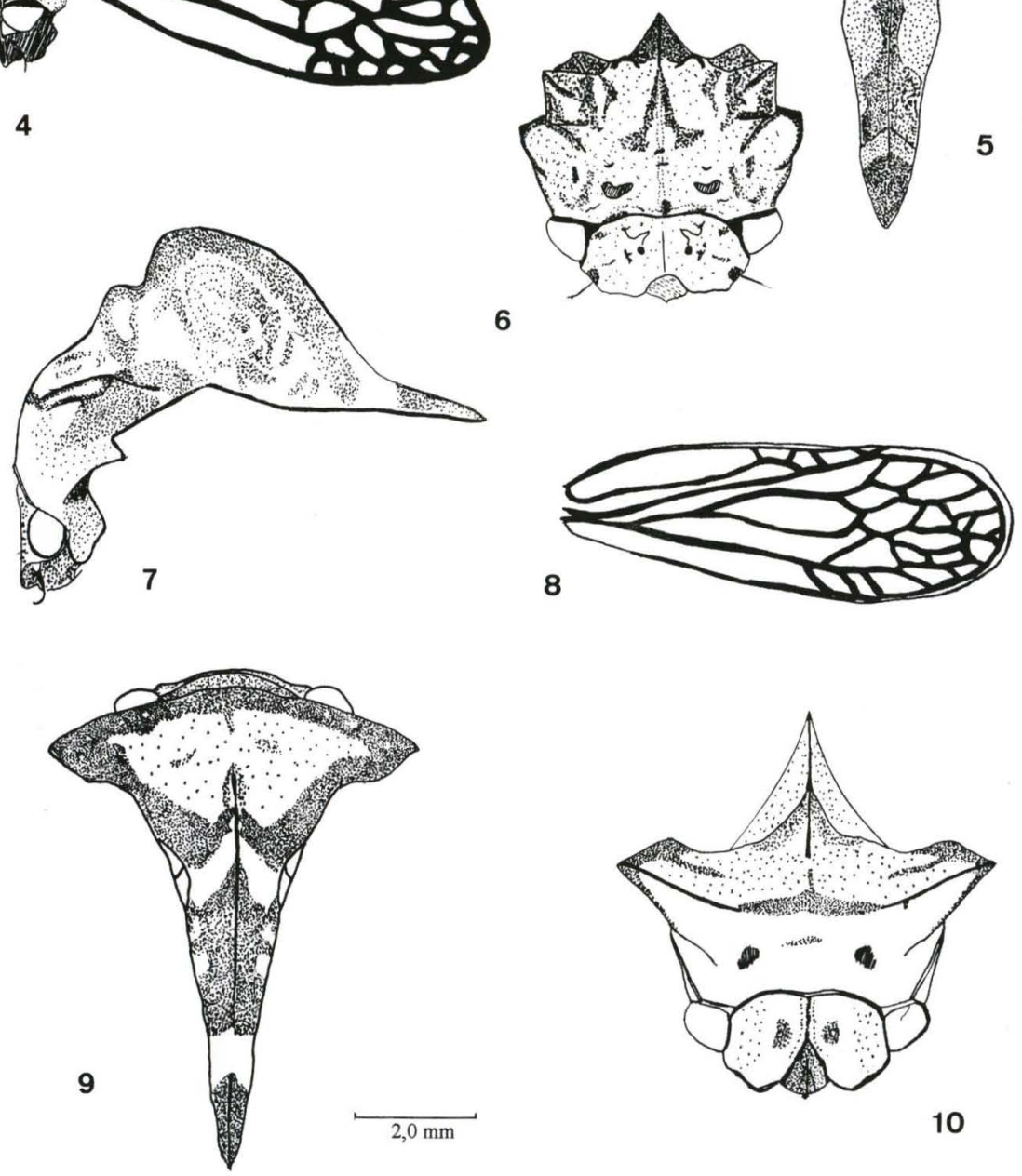

5

6
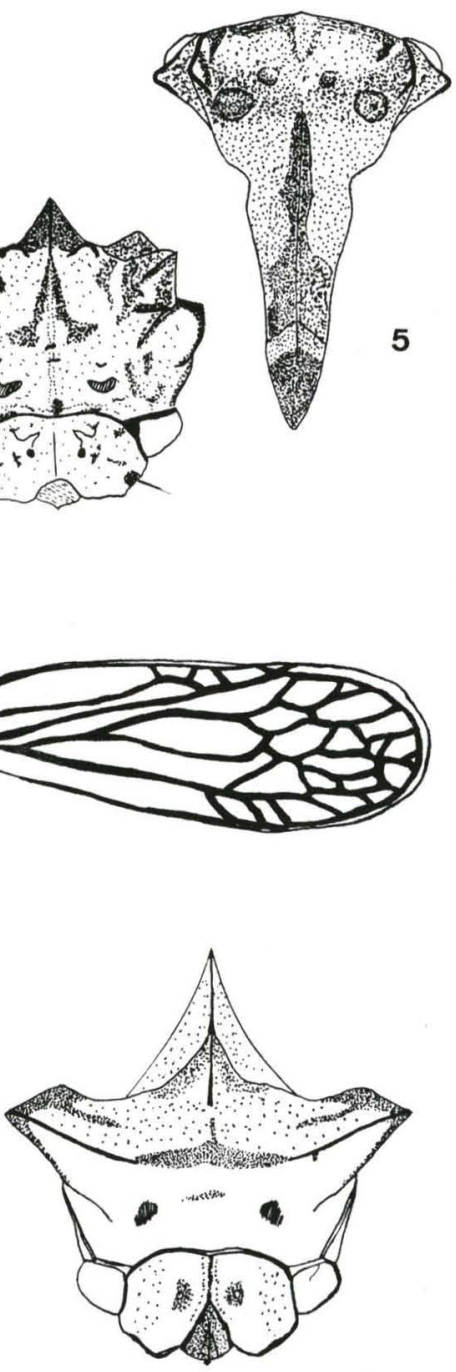

10

Figs 4-10. (4-6) Centronodus bilobatus sp. n.: (4) cabeça, pronoto e tégmina, vista lateral; (5) pronoto, vista dorsal; (6) cabeça e pronoto, vista frontal; (7-10) C. bolivianus sp. n.: (7) cabeça e pronoto, vista lateral; (8) tégmina; (9) pronoto, vista dorsal; (10) cabeça e pronoto, vista frontal. 


\section{Centronodus magnificus sp. $\mathbf{n}$.}

Figs $3,11-15$

Diagnose. De porte relativamente grande, com processos supra-umerais bem desenvolvidos, mais ou menos prismáticos e achatados; elevação dorsal bem evidente, com o cume regularmente arqueado, precedida por um pequeno dente rombo localizado entre os processos supra-umerais e a elevação dorsal.

Medidas (mm). Macho/fêmea. Comprimento total, 10,83/12,17; comprimento do pronoto, 9,67/11,00; largura da cabeça, 3,67/4,00; comprimento da cabeça, 1,83/2,33; largura entre os ângulos umerais, 4,50/4,83; distância entre os ápices dos processos supra - umerais, 6,83/7,83; comprimento dos processo supra - umerais, 2,33/3,00; altura do espinho dorsal, 0,50/0,50; altura da elevação dorsal, 2,25/2,75; comprimento das tégminas, 9,17/10,00; comprimento das asas, $8,00 / 9,17$.

Descrição. Holótipo macho. Cabeça sub-quadrangular, de coloração castanho-clara, com manchas e pontos castanho-escuros; clípeo mais longo que largo, piriforme, com o bordo inferior ultrapassando a margem dos lóbulos supra-antenais, com o ápice voltado para trás; sutura epistomal arqueada; lóbulos supra-antenais com superfície plana, textura lisa, margens foliáceas, arredondadas; espaços interocelar e ocelo-oculares planos; ocelos situados abaixo da linha imaginária que passa pelo centro dos olhos, mais próximos entre si que dos olhos; sutura coronal atingindo a margem superior do clípeo. Pronoto visto frontalmente, castanho-claro com máculas e pontos castanho-escuros; lateralmente castanho-escuro com uma faixa amarelo-pálida na área pré-apical; carena dorsal saliente; superfície dos lóbulos pós-oculares pontuada; metopídio plano; distância entre os ângulos umerais menor que o espaço entre os ápices dos processo supra-umerais; processos supra-umerais de forma cônica, achatada, dirigidos para os lados e para cima, ápice com carena pronunciada na área anterior; superfície dos processos supra-umerais pontuada; margem anterior da elevação dorsal arredondada, declive posterior leve; escutelo totalmente visível; ápice do pronoto gradativamente agudo. Tégminas com a área basal coriácea, com o mesmo padrão de coloração do pronoto, com algumas manchas castanho-claras, margem distal enfumaçada, translúcida. Asas hialinas com venação castanho-escura. Pernas castanho-claras com manchas castanho-escuras, tíbias tricarenadas, cobertas com cerdas, sendo as posteriores com duas fileiras de espinhos bem desenvolvidos. Genitália. Macho: edeago mais ou menos comprimido lateralmente, lanceolado, encurvado para cima, com as bordas microdenticuladas desde o ápice até a falobase; esta de forma cilíndrica; parâmeros bem desenvolvidos, de forma cilíndrica, área apical em forma de gancho; conectivo com a base larga, e com a área que se conecta ao edeago estreita e curta.

Fêmea. Com as mesmas características do macho, porém um pouco maior.

Material examinado. Holótipo macho, com os seguintes dados: "Corcovado-Rio de Janeiro-Brasil, 03:XI:1958, Alvarenga \& Seabra leg." Parátipos: 2 machos de Corcovado, Rio de Janeiro, Brasil, XI-1958, Alvarenga \& Seabra leg., 1 macho, ibidem, X-1958; 1 macho, ibidem, 15-XII-1958, idem. Fêmeas: 1 fềmea de Represa Rio Grande -Guanabara [Rio de Janeiro] - Brasil X-1960, F.M. Oliveira 

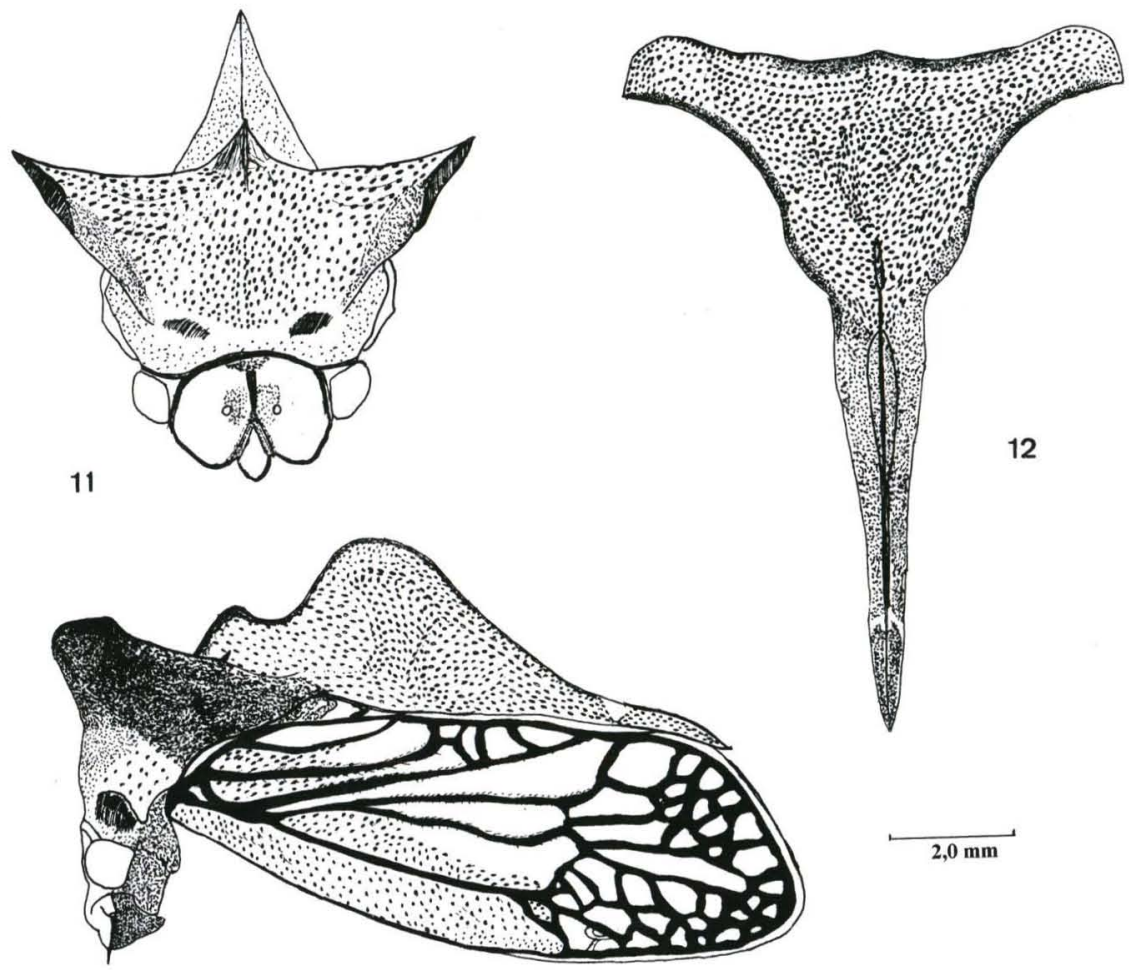

13
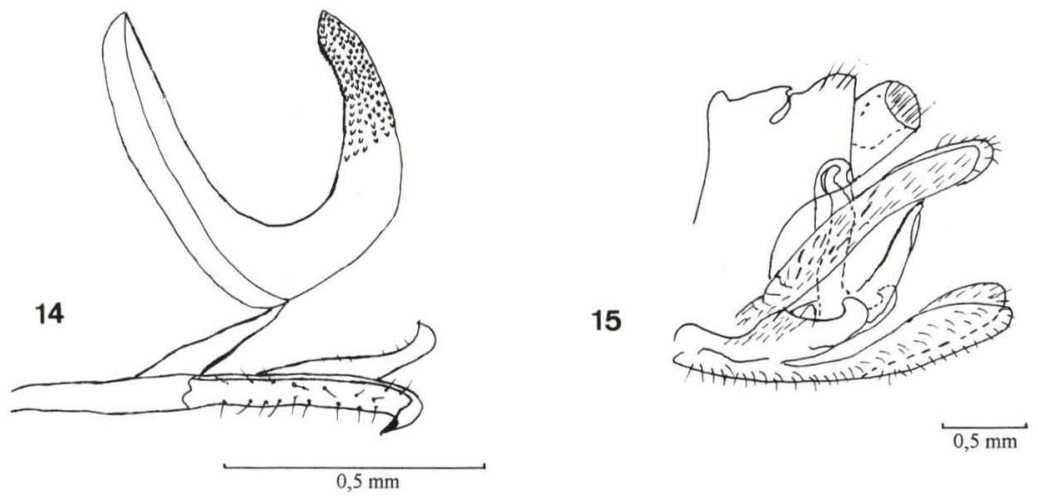

Figs 11-15. Centronodus magnificus sp. n. (11) cabeça e pronoto, vista frontal; (12) pronoto, vista dorsal; (13) cabeça, pronoto e tégmina, vista lateral; (14) edeago, conetivo e parâmeros; (15) vista lateral da genitália. 
leg., 1 fêmea, ibidem, 15 II 1967, idem., 1 fêmea, ibidem, 01: I:1972 idem, 1 fềmea, ibidem, II:1961, Seabra \& Alvarenga leg., 1 de Corcovado - Guanabara [Rio de Janeiro] - Brasil I-XII-1966, Moure \& Seabra leg. (DZUP).

Etimologia. O nome específico é alusivo ao seu grande porte, em comparação com as outras espécies.

Comentários. Está espécie é próxima de $C$. denticulus Fonseca no seu aspecto geral; difere entretanto, pela elevação dorsal menos pronunciada e pela posição do espinho dorsal que fica eqüidistante dos processos supra-umerais e da elevação dorsal. Processos supra-umerais com os ápices foliáceos, levemente dirigidos para trás.

AGRADECIMENTOS. Os nossos melhores agradecimentos ao Dr. Stuart McKamey e também ao Dr. Thomas Henry, ambos do National Museum of Natural History, Washington, D.C., que sempre têm atendido aos nossos pedidos de empréstimo.

\section{REFERÊNCIAS BIBLIOGRÁFICAS}

DerTz, L.L. 1975. Classification of the higher categories of the New World Treehoppers (Homoptera: Membracidae). North Carolina State University, Agricultural Experiment Station. Tech. Bull. 225: $1-177$

Deitz, L.L \& C.H. Dietrich. 1993. Superfamily Membracoidea (Homoptera: Auchenorrhyncha). I. Introduction and revised classification with new family-group taxa. Syst. Entomol. 18: 287-296.

FonSECA, J.P. DA. 1940. Contribuição para o conhecimento dos membracídeos neotrópicos (III). Arq. Inst. Biológico 11: 133-138.

. 1974. Uma nova espécie do gênero Centronodus Funkhouser (Homoptera, Membracidae). Revta bras. Ent. 18 (4): 129-131.

FUNKHOUSER, W.D. 1930. New genera and species of Neotropical Membracidae. Jour. N.Y. Entomol. Soc. 38: $405-421$.

Recebido em 14.XI.2000; aceito em 27.VI.2001. 